\title{
Nephrogenic Diabetes Insipidus with New-Onset Diabetic Ketoacidosis in a Child- Challenges in Fluid and Electrolyte Management
}

Yu-Shan Tseng ( $\nabla$ yushan.tseng@carle.com )

Carle Foundation Hospital https://orcid.org/0000-0001-5513-424X

Nicole Swaney

Children's Hospital of Michigan

Katherine Cashen

Duke University School of Medicine

Amrish Jain

Children's Hospital of Michigan

Nina Ma

Children's Hospital of Michigan

Andrew Prout

Children's Hospital of Michigan

\section{Research Article}

Keywords: Child, Nephrogenic Diabetes Insipidus, Diabetic Ketoacidosis, Shock, Hyperosmolarity

Posted Date: November 15th, 2021

DOI: https://doi.org/10.21203/rs.3.rs-1056558/v1

License: (1) This work is licensed under a Creative Commons Attribution 4.0 International License.

Read Full License

Version of Record: A version of this preprint was published at Pediatric Nephrology on March 14th, 2022. See the published version at https://doi.org/10.1007/s00467-022-05436-1. 


\section{Abstract}

\section{Background}

Intensive care management of diabetic ketoacidosis (DKA) is targeted to reverse ketoacidosis, replace the fluid deficit, and correct electrolyte imbalances. Adequate restoration of circulation and treatment of shock is key. Pediatric treatment guidelines of DKA have become standard but complexities arise in children with co-morbidities. Congenital nephrogenic diabetes insipidus (NDI) is a rare hereditary disorder characterized by impaired renal concentrating ability and treatment is challenging. NDI and DKA together have only been previously reported in one patient.

\section{Case Diagnosis/Treatment}

We present the case of a 12-year-old male with NDI and new onset DKA with hyperosmolality. He presented in hypovolemic shock with altered mental status. Rehydration was challenging and isotonic fluid resuscitation resulted in increased urine output and worsening hyperosmolar state. Use of hypotonic fluid and insulin infusion led to lowering of serum osmolality faster than desired and increased the risk for cerebral edema. Despite the rapid decline in serum osmolality his mental status improved so we allowed him to drink free water mixed with potassium phosphorous every hour to match his urinary output (1:1 replacement) and continued $0.45 \%$ sodium chloride based on his fluid deficit and replacement rate with improvement in his clinical status.

\section{Conclusions}

This case illustrates the challenges of managing hypovolemic shock, hyperosmolality, and extreme electrolyte derangements driven by NDI and DKA.

\section{Introduction}

Diabetes insipidus (DI) and diabetic ketoacidosis (DKA) are both characterized by polyuria and compensatory polydipsia but differ fundamentally in pathophysiology and management. DI may be central or nephrogenic (NDI). NDI is caused by renal insensitivity to ADH and may be hereditary or acquired ${ }^{1}$.

Type 1 diabetes mellitus (T1DM) is due to deficient insulin secretion from the pancreas and DKA is a metabolic emergency characterized by hyperglycemia, ketosis, and acidosis. Hyperglycemia causes osmotic diuresis, and patients present with dehydration and electrolyte derangements.

Concurrent DKA and NDI exacerbation is extremely rare, with only one case reported in the literature ${ }^{2}$. Here, we present a 12-year-old male with NDI and DKA. This paper focuses on the challenges in managing this child's fluid status and electrolyte derangements, as both disease processes drive excessive urine output, electrolyte and acid-base imbalances, and rapid fluctuation in osmolality. 


\section{Case Presentation}

A 12-year-old male with NDI managed with amiloride and hydrochlorothiazide (HCTZ) presented with vomiting for three days. He had severe electrolyte derangements, hypovolemic shock, altered mental status, and polydipsia. Past medical history was significant for nonverbal autism for which he takes clonidine and fluoxetine. At baseline he is interactive, playful, and ambulatory. His NDI was diagnosed at 4 months of age due to severe failure to thrive and he had positive AVPR2 mutation on genetic testing. At baseline, he drinks $4-5$ liters of fluid per day to match his urine output. Parents closely track urine output and measure his oral intake of fluids to match his output and brought him to the emergency department because of altered mental status.

He presented to the emergency department (ED) tachycardic with heart rate 140 beats/min, respiratory rate 36 breaths/min, and hypothermic to $34.1 \otimes \mathrm{C}$. Blood pressure was 126/73 $\mathrm{mm} \mathrm{Hg}$ and oxygen saturation was $98 \%$ on room air. On exam, he was dehydrated, lethargic, and altered. He was pale with sunken eyes. He had bilateral lower extremity clonus and stereotactic movements. Venous blood gas showed mixed metabolic acidosis and respiratory alkalosis with lactate of $4.2 \mathrm{mmol} /$ liter. He was hyperglycemic, hyperosmolar, with high corrected sodium level. HemoglobinA1C and beta hydroxybutyrate levels were significantly elevated confirming the diagnosis of DKA (Table1.)

Patient was initiated on our DKA treatment protocol. He received 1-liter normal saline bolus and was started on $0.9 \%$ sodium chloride with $20 \mathrm{mEq}$ potassium-acetate and $20 \mathrm{mEq}$ potassium-phosphate at 1.5 times maintenance rate. Insulin infusion was started at $0.05 \mathrm{units} / \mathrm{kg} / \mathrm{hr}$. In the ED he was allowed to drink 3 liters of unrestricted free water. He was then admitted to the pediatric intensive care unit. 
Table 1

Initial Laboratory Results

\begin{tabular}{|c|c|c|}
\hline & Patient's initial laboratory results & Reference ranges (with units) \\
\hline Sodium & 135 & $135-145 \mathrm{mMol} / \mathrm{L}$ \\
\hline Potassium & 3.7 & $3.5-5.1 \mathrm{mMol} / \mathrm{L}$ \\
\hline Chloride & 95 & $98-107 \mathrm{mMol} / \mathrm{L}$ \\
\hline Bicarbonate & 12 & $21-31 \mathrm{mMol} / \mathrm{L}$ \\
\hline Anion Gap & 28 & $5-15 \mathrm{mMol} / \mathrm{L}$ \\
\hline Glucose & 949 & $75-105 \mathrm{mg} / \mathrm{dL}$ \\
\hline Urea Nitrogen (BUN) & 17 & $7-25 \mathrm{mg} / \mathrm{dL}$ \\
\hline Creatinine & 0.82 & $0.2-0.4 \mathrm{mg} / \mathrm{dL}$ \\
\hline Calcium & 11.1 & $8.6-10.3 \mathrm{mg} / \mathrm{dL}$ \\
\hline Magnesium & 2.8 & $1.5-2.6 \mathrm{mg} / \mathrm{dL}$ \\
\hline Phosphorus & 2.8 & $4.3-6.8 \mathrm{mg} / \mathrm{dL}$ \\
\hline Total Protein & 9.1 & $5.9-7.2 \mathrm{gm} / \mathrm{dL}$ \\
\hline Albumin & 5.4 & $3.8-4.7 \mathrm{gm} / \mathrm{dL}$ \\
\hline Osmolality & 360 & $275-305 \mathrm{mOsm} / \mathrm{kg}$ \\
\hline Hemoglobin A1c & $10.4 \%$ & $4.0-6.0 \%$ \\
\hline Beta-hydroxybutyrate & 64 & $0.2-2.8 \mathrm{mg} / \mathrm{dL}$ \\
\hline \multicolumn{3}{|l|}{ Urinalysis } \\
\hline $\mathrm{pH}$ & 5.0 & $4.8-8$ \\
\hline Specific Gravity & $<=1.005$ & $1.005-1.025$ \\
\hline Glucose & $2+$ & Negative \\
\hline Ketones & $3+$ & Negative \\
\hline Blood & Negative & Negative \\
\hline Protein & Negative & Negative \\
\hline Bilirubin & Negative & Negative \\
\hline Urobilinogen & 0.2 & $0.1-1.0 \mathrm{mg} / \mathrm{dL}$ \\
\hline Nitrite & Negative & Negative \\
\hline
\end{tabular}




\begin{tabular}{|lll|}
\hline & Patient's initial laboratory results & Reference ranges (with units) \\
\hline Leukocytes & Negative & Negative \\
\hline Venous Blood Gas & & \\
\hline $\mathrm{pH}$ & 7.49 & $7.30-7.40$ \\
\hline $\mathrm{PCO}_{2}$ & 16.5 & $40-50 \mathrm{mmHg}$ \\
\hline $\mathrm{PO}_{2}$ & 101 & $42-48 \mathrm{mmHg}$ \\
\hline Bicarbonate & 12 & $21-31 \mathrm{mMol} / \mathrm{L}$ \\
\hline Base Excess & -7 & $-2-2 \mathrm{mMol} / \mathrm{L}$ \\
\hline Lactate & 4.25 & $1.13-1.27 \mathrm{mMol} / \mathrm{L}$ \\
\hline
\end{tabular}

\section{Hospital Course}

He spent 3 hours in the ED and initially mental status improved but repeat glucose testing showed a rapid decline from $949 \mathrm{mg} / \mathrm{dL}$ to $532 \mathrm{mg} / \mathrm{dL}$, osmolality also rapidly declined from $360 \mathrm{mOsm} / \mathrm{kg}$ to 293 $\mathrm{mOsm} / \mathrm{kg}$. Corrected sodium went from $155 \mathrm{mEq} / \mathrm{L}$ to $132 \mathrm{mEq} / \mathrm{L}$. Oral intake was then stopped with the goal of decreasing the rapid decline in serum osmolality. However, he continued to have brisk urine output and attempts to replace with bolus isotonic fluid IV only drove the diuresis. Within 4 hours, he was negative $1.2 \mathrm{~L}$, and his clinical status worsened with sunken eyes, agitation, and tachycardia.

We restarted home HCTZ and amiloride and he was allowed to drink water to replace his hourly urine output (1:1 replacement). Intravenous fluid (IVF) was changed to $0.45 \%$ sodium chloride and kept at the rate of 1.5 times maintenance. After 12 hours, he had continued altered mental status, severe hypokalemia $(1.7 \mathrm{mEq} / \mathrm{L})$, and hypophosphatemia $(<1.0 \mathrm{mg} / \mathrm{dL})$ despite aggressive intravenous electrolyte replacement. He developed significant respiratory alkalosis with pH 7.77, PCO2 of 10, and worsened lactic acidosis ( $6 \mathrm{mmol} / \mathrm{L}$.) He had brief runs of accelerated junctional rhythm on telemetry. Central venous access was obtained and electrolyte replacement continued. We added the maximum amount to IVF and provided continuous replacements IV. He was taken for magnetic resonance imaging and magnetic resonance venography that was negative for cerebral edema or sinus venous thrombosis.

Hypokalemia, hypophosphatemia, and respiratory alkalosis slowly improved with aggressive intravenous electrolyte replacement. He continued to have altered mental status but was protecting his airway and to maximize his electrolyte replacement, we dissolved $500 \mathrm{mg}$ potassium-phosphate tablets in the free water (2 tablets per $1 \mathrm{~L}$ ). He was drinking to match his urine output (1:1). Ketosis also resolved so he was transitioned to subcutaneous insulin via pump. Mental status improved to near baseline. On day 2 of admission despite improved clinical and laboratory parameters he developed a generalized tonic-clonic seizure lasting 30 seconds. This was thought to be secondary to hyponatremia (Sodium $130 \mathrm{mEq} / \mathrm{L}$ ) as his IVF had been cut to half-maintenance and he was unrestricted in his enteral water intake. His sodium 
was replenished and he did not have additional seizures. He was discharged home on oral electrolyte supplements and insulin pump to follow with nephrology and endocrinology.

\section{Discussion}

The preferred method of rehydration in an NDI patient is enteral. However, hypotonic IVF are preferred if the patient cannot tolerate oral intake. Guarino et al. report the case of a 21-month-old with NDI with viral gastritis and severe dehydration rehydrated with $5 \%$ dextrose in sterile water IV ${ }^{3}$. The ideal IV rehydration fluid in NDI is unclear as fluids with higher osmolality than a patient's urine osmolality will increase overall sodium load, driving further diuresis and worsening hypernatremic dehydration. Severe hypernatremic dehydration can lead to seizures, sinus venous thrombosis, and cerebral hemorrhage ${ }^{4-7}$. If an NDI patient presents with shock, isotonic fluid boluses should always be used for volume resuscitation. But replacing the fluid deficit with extremely hypotonic fluid runs the risk of rapid decline in serum sodium and osmolality. For DKA, the preferred initial IVF is isotonic fluid. IVF containing dextrose can worsen hyperglycemia, and hypotonic fluids may drop osmolality too rapidly, risking cerebral edema ${ }^{8,9}$. Both these disease processes are challenging alone but together are extremely difficult to manage. We suggest starting a child with NDI and DKA on $0.45 \% \mathrm{NaCl}$ after isotonic fluid boluses then closely monitoring the fluid status, blood sugar, and serum osmolality to determine concentration of ongoing fluid replacement.

Initially we had difficulty maintaining hydration status and preventing rapid decrease in serum osmolality in our patient. He was started on normal saline intravenously in the ED at 1.5x maintenance and was allowed to drink free water. The salt load from normal saline increased his urine output, he then drank $3 \mathrm{~L}$ of free water resulting in the rapid drop of glucose and serum osmolality. Despite this rapid decline in osmolality his mental status improved. However, when oral intake was restricted, we could not keep up with his urine output with isotonic IVF alone, and he again became significantly dehydrated with worsening mental status.

To our knowledge only one other case has been reported in the literature of a child with NDI and DKA ${ }^{2}$. This 16-year-old with NDI and DKA presented with $\mathrm{pH} \mathrm{7.13,} \mathrm{bicarbonate} 13 \mathrm{mmol} / \mathrm{L}$, and betahydroxybutyrate $7.75 \mathrm{mmol} / \mathrm{L}$. and initial glucose $1065 \mathrm{mg} / \mathrm{dL}$. He was rehydrated with $5 \%$ dextrose $0.2 \%$ sodium chloride at a rate of 1.5 times maintenance IVF. He was allowed to drink $250 \mathrm{~mL}$ of free water hourly. DKA resolved 13 hours after initiation of treatment. This case helped guide management for our patient. Our patient was sicker than the reported patient in that he presented in shock, with severe electrolyte abnormalities and was younger in age and nonverbal making management even more challenging. We did not add dextrose to his IVF given labile serum glucose levels. We used $0.45 \%$ sodium chloride instead of $0.2 \%$ sodium chloride because this was too hypotonic in a child who initially had rapid decline in serum osmolality. We allowed our patient to drink free water mixed with dissolved potassiumphosphate to replace his hourly urinary output. The patient's hydration status improved, and his osmolality decreased gradually. 
Our patient's extreme electrolyte derangements (hypokalemia, hypophosphatemia, and hyponatremia) despite aggressive replacement made this case difficult to manage. Due to these derangements, he developed accelerated junctional rhythm and a brief tonic-clonic seizure. Our patient required central line placement which we try to avoid for hyperosmolar patients due to the risk of thrombosis for aggressive potassium and phosphate repletion.

Finally, this patient had respiratory alkalosis at baseline on review of previous blood gases. His respiratory alkalosis was exacerbated with dehydration and improved when he slept suggesting central causes. We performed an extensive workup for respiratory alkalosis, which was negative. This child had significant stereotactic movements and mild tachypnea while awake around medical personnel suggesting that the pathophysiology was central nervous system related.

\section{Conclusion}

No guidelines exist for the management of concurrent DKA and NDI and only one other child has been reported in the literature to help guide fluid resuscitation for this challenging presentation. Our case was complicated by shock, extreme electrolyte derangements, seizure, and respiratory alkalosis. This novel case highlights the complex fluid and electrolyte management needed for children with NDI and new onset DKA.

\section{Declarations}

\section{Funding:}

The authors did not receive support from any organization for the submitted work.

The authors declare they have no financial interests.

\section{Ethical Review:}

This Central Michigan University Institutional Review Board deemed this study exempt and in accordance with the ethical standards of our institution and with the 1964 Helsinki Declaration and its later amendments or comparable ethical standards.

\section{Consent:}

The patient's mother has given consent to report the patient's case in the medical literature. The mother understands that patient's identification information will not be published, but anonymity cannot be guaranteed.

\section{References}


1. Kavanagh C, Uy NS (2019) Nephrogenic Diabetes Insipidus. Pediatr Clin North Am 66(1):227-234. doi:10.1016/j.pcl.2018.09.006

2. De Sa HA, Chung S, Shaniuk PM (2021) Sweet and Salty: Diabetic Ketoacidosis in a Patient With Nephrogenic Diabetes Insipidus. Cureus 13(1):e12682. doi:10.7759/cureus.12682

3. Guarino S, Diplomatico M, Marotta R et al (2020) Nephrogenic Diabetes Insipidus in Childhood: Assessment of Volume Status and Appropriate Fluid Replenishment. Pediatr Emerg Care 36(7):e402-e404. doi:10.1097/PEC.0000000000001438

4. Schwaderer AL, Schwartz GJ (2005) Treating Hypernatremic Dehydration. Pediatr Rev 26(4):148150. doi:10.1542/pir.26-4-148

5. Fleischer LM, Wilson TA, Parker MM (2007) Hypernatremic dehydration, diabetes insipidus, and cerebral venous sinus thrombosis in a neonate: a case report. J Med Case Reports 1:66. doi:10.1186/1752-1947-1-66

6. Jani S, Ariss R, Velumula P, Altinok D, Chawla S (2020) Term Infant with Cerebral Venous Sinus Thrombosis. Case Rep Pediatr 2020:8883007. doi:10.1155/2020/8883007

7. Mata LS, Gusmão D, de Almeida ARP (2010) Hypernatremic hemorrhagic encephalopaty: case report and literature review. Rev Bras Ter Intensiva 22(3):305-309

8. Wolfsdorf JI, Glaser N, Agus M et al (2018) ISPAD Clinical Practice Consensus Guidelines 2018: Diabetic ketoacidosis and the hyperglycemic hyperosmolar state. Pediatr Diabetes 19:155-177. doi:10.1111/pedi.12701

9. Agrawal S, Baird GL, Quintos JB et al (2018) Pediatric Diabetic Ketoacidosis with Hyperosmolarity: Clinical Characteristics and Outcomes. Endocr Pract 24(8):726-732. doi:10.4158/EP-2018-0120 